\title{
Theoretical and experimental analysis of the performances of a heat sink with vertical orientation in natural convection
}

\author{
Mario Cucumo • Vittorio Ferraro • \\ Dimitrios Kaliakatsos • Valerio Marinelli
}

Received: 2 July 2014/ Accepted: 9 October 2014/Published online: 25 October 2014

(C) The Author(s) 2014. This article is published with open access at Springerlink.com

\begin{abstract}
In the various areas in which electrical components are used, the problem of heat dissipation generated due to the absorption of electrical energy assumes great interest and is worthy of an in-depth study. In steady state conditions, the thermal power generated can equal the electrical power absorbed and leads to an alteration in the physical properties of electrical components compromising their performance and correct functioning. One of the most frequently adopted solutions consists in the application of a heat sink on the surface to be cooled. Experimental tests were conducted using an infrared thermal camera, an internal climate control unit for the recording of the thermo hygrometric conditions of the environment and a finite element software (ProENGINEER) to simulate the thermal behaviour of the heat sink in order to analyse the modalities of thermal exchange of the heat sink. The results obtained were subsequently compared with the heat sink properties provided by the manufacturer. The main objective of the work is that of providing a methodology that blends the use of thermographic and simulation techniques with finite elements, in order to render the development of a theoretical-experimental correlation possible for any physical condition and geometrical configuration taken into
\end{abstract}

M. Cucumo · V. Ferraro · D. Kaliakatsos $(\bowtie) \cdot$ V. Marinelli Department of Mechanical, Energetics and Management Engineering (DIMEG), University of Calabria, Via P. Bucci, Cubo 44C, 87036 Rende, CS, Italy

e-mail:dimitri@unical.it

M. Cucumo

e-mail:m.cucumo@unical.it

V. Ferraro

e-mail: vittorio.ferraro@unical.it

V. Marinelli

e-mail: v.marinelli@unical.it consideration. This methodology is confirmed in the field of technological development of electrical components, where at each stage of the planning process exists a marked intertwining of computing, electronics, mechanics and heat transmission.

Keywords Theoretical - Experimental · Performances · Vertical · Heat sink

\section{List of symbols}

$B \quad$ Baseplate width (mm)

D Fin thickness (mm)

$H \quad$ Length of the heat sink (mm)

$h_{\text {ave }} \quad$ Average convective heat exchange coefficient $\left(\mathrm{Wm}^{-2} \mathrm{~K}^{-1}\right.$ )

$h_{\text {calc }} \quad$ Calculated convective heat exchange coefficient $\left(\mathrm{Wm}^{-2} \mathrm{~K}^{-1}\right)$

$h_{\text {cav }} \quad$ Central cavity convective heat exchange coefficient $\left(\mathrm{Wm}^{-2} \mathrm{~K}^{-1}\right)$

$h_{\text {corr }} \quad$ Convective heat exchange coefficient calculated by the correlation $\left(\mathrm{Wm}^{-2} \mathrm{~K}^{-1}\right)$

$h_{\text {esp }} \quad$ Fin exposed surface convective coefficient $\left(\mathrm{Wm}^{-2} \mathrm{~K}^{-1}\right)$

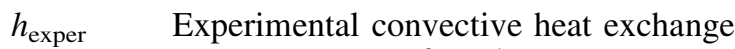
coefficient $\left(\mathrm{Wm}^{-2} \mathrm{~K}^{-1}\right)$

$h_{\text {estr }} \quad$ Fin external surface convective coefficient $\left(\mathrm{Wm}^{-2} \mathrm{~K}^{-1}\right.$ )

$h_{\text {int }} \quad$ Fin internal surface convective coefficient $\left(\mathrm{Wm}^{-2} \mathrm{~K}^{-1}\right)$

$h_{\text {mean }} \quad$ Mean convective heat exchange coefficient for all surfaces of heat skin $\left(\mathrm{Wm}^{-2} \mathrm{~K}^{-1}\right)$

$K \quad$ Thermal conductance of baseplate $\left(\mathrm{Wm}^{-1} \mathrm{~K}^{-1}\right.$ )

$L \quad$ Height of the fins of the heat sink (mm) MB Mean error 
$n \quad$ Optimal number of fins

$Q_{\mathrm{d}} \quad$ Dissipated thermal power (W)

$Q_{\text {exper }} \quad$ Experimental dissipated power (W)

$Q_{\text {manufact }}$ With manufacturer's data dissipated power (W)

$R_{\text {exper }} \quad$ Experimental thermal resistance $\left(\mathrm{m}^{2} \mathrm{KW}^{-1}\right)$

$R_{\text {manufact }}$ Manufacturer's thermal resistance $\left(\mathrm{m}^{2} \mathrm{KW}^{-1}\right)$

$R_{\mathrm{th}} \quad$ Thermal resistance between the junction and external environment $\left(\mathrm{m}^{2} \mathrm{KW}^{-1}\right)$

RMS Root mean square

$S \quad$ Fin spacing (mm)

$S_{\text {cav }} \quad$ Central cavity surface $\left(\mathrm{m}^{2}\right)$

$S_{\text {esp }} \quad$ Exposed fin surface $\left(\mathrm{m}^{2}\right)$

$S_{\text {estr }} \quad$ Fin external surface at extremities $\left(\mathrm{m}^{2}\right)$

$S_{\text {int }} \quad$ Fin internal surface $\left(\mathrm{m}^{2}\right)$

$S_{\text {opt }} \quad$ Optimal fin spacing (mm)

$t_{\mathrm{a}} \quad$ Air inside cavities temperature $\left({ }^{\circ} \mathrm{C}\right)$

$t_{\text {cav }} \quad$ Central cavity surface temperature $\left({ }^{\circ} \mathrm{C}\right)$

$t_{\text {esp }} \quad$ Exposed fin surface temperature $\left({ }^{\circ} \mathrm{C}\right)$

$t_{\text {estr }} \quad$ Temperature of the external surface of the fins at extremities $\left({ }^{\circ} \mathrm{C}\right)$

$t_{\text {int }} \quad$ Internal fin surface temperature $\left({ }^{\circ} \mathrm{C}\right)$

$t_{\text {film }} \quad$ Film temperature $\left({ }^{\circ} \mathrm{C}\right)$

$t_{\max } \quad$ Maximum heat sink temperature $\left({ }^{\circ} \mathrm{C}\right)$

$t_{\text {mean }} \quad$ Average heat sink temperature $\left({ }^{\circ} \mathrm{C}\right)$

$t_{\mathrm{p}} \quad$ Fin surface temperature $\left({ }^{\circ} \mathrm{C}\right)$

\section{Greek symbols}

$\Delta T_{\text {exper }}$ Experimental temperature difference $\left({ }^{\circ} \mathrm{C}\right)$

$\varepsilon \quad$ Percentage error

\section{Introduction}

The passing of current in semiconductors causes, due to the Joule effect, a generation of heat which determines an increase in the temperature of the element.

In a steady state condition, the dissipated thermal power $Q_{\mathrm{d}}$ is equal to:

$Q_{\mathrm{d}}=\frac{t_{\mathrm{p}}-t_{\mathrm{a}}}{R_{\mathrm{th}}}$

The equivalent thermal resistance between the junction and the external environment $R_{\text {th }}$ is the parameter which characterises the efficiency of a heat sink. Such resistance is supplied by the manufacturer and is defined as the increase in temperature undergone due to the application of an active electrical power of $1 \mathrm{~W}$.

The component to be cooled is placed in contact with the heat sink, which presents high thermal conductivity and a high external surface due to its particular geometry (finning), with the aim of favouring convective and radiative heat exchange with the external environment. It is therefore possible to argue that the heat sink does nothing

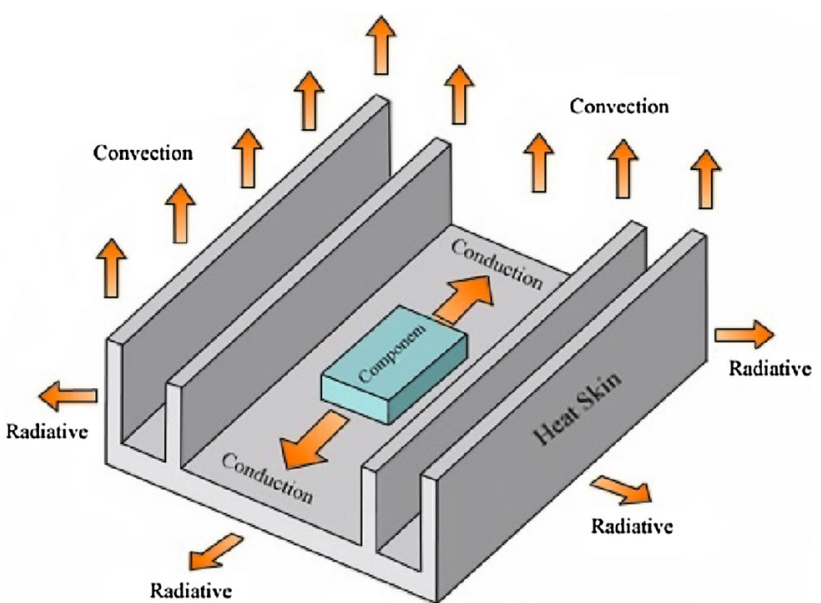

Fig. 1 Heat sink functioning

but reduce the thermal resistance between the component and the external environment.

In order to optimise heat conduction through the component and the heat sink, it is opportune to smooth the contact surface to obtain the greatest contact area between the two, thus reducing roughness to a minimum. However, since it is not possible to guarantee a perfect result in polishing and therefore in the elimination of any possible air interspace (increase in thermal resistance), use is made of highly conductive greases, such as silicone grease with silver, zinc or copper oxides.

To evaluate the radiative heat exchange of a heat sink, it is necessary to take into consideration different factors which characterise its functioning, such as the surface finish or the surface colour. Rough or shiny surface reduces heat sink efficiency and increase thermal resistance, while a dark colour consents heat sink thermal behaviour that is close to that of a 'black body', thus increasing thermal exchange efficiency.

The parametrical study of the heat sink was extensively addressed by Kraus and Bar-Cohen [1]. Elenbaas [2] was the first to create a detailed study on heat sink fins. Instead, Starner and McManus [3], Welling and Wooldridge [4] carried out several experimental studies, while Van de Pol and Tierney [5] developed a correlation with Welling and Woolridge's experimental results. Finally, Bilitsky [6] has carried out a complete parametrical analysis of heat sinks in relation to the height and thickness of the fins.

A simple and commonly used fin configuration is that obtained by using different parallel fins on a baseplate that exchanges mainly by conduction (Fig. 1). In this case, the viscous resistances in the cavity between the two adjacent fins can assume, according to the distance between the two surfaces, notable importance and reduce the value of the convective heat exchange coefficient. The optimal spacing assumes importance in the case of large surfaces in order to 


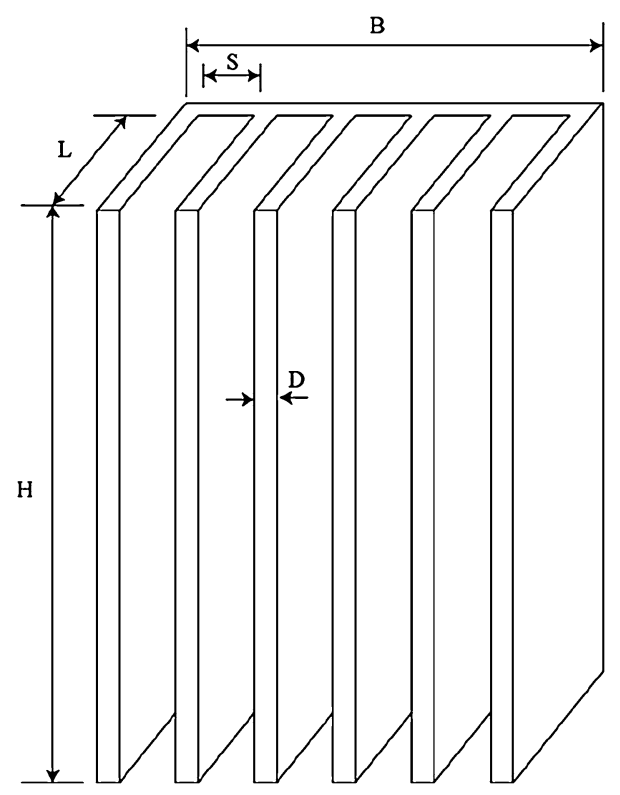

Fig. 2 Extended surface with continuous vertical fins

obtain the best equilibrium value between the opposing effects provided by the number of fins (greater exchange surface) and by the viscosity. The optimal choice is that which maximises the dissipated power for a given base area.

In Ref. [1], Kraus and Bar-Cohen provide relations for the obtainment of the optimal distance $S_{\text {opt }}$ for isotherm fins, whose thickness $D$ is much smaller than the distance $S$ between the fins (Fig. 2).

$S_{\text {opt }}=2.714 \frac{H}{\sqrt[4]{R a}}$

where $R a$ is the dimensionless Rayleigh number and $H$ is the fin length.

The average convective heat exchange coefficient for a vertical plate is equal to:

$h_{\mathrm{ave}}=1.31 \frac{K}{S_{\mathrm{opt}}}$

where $K$ is the thermal conductance coefficient of the baseplate.

The optimal number of fins $n$ is defined by the relation:

$n=\frac{B}{S_{\mathrm{opt}}+D}$

where $B$ is the width of the baseplate.

\section{Description of the heat sink and instruments used}

The heat sink used for the test (Fig. 3) is in black anodised aluminium in order to favour radiative heat exchange and has two series of continuous fins and a central cavity.

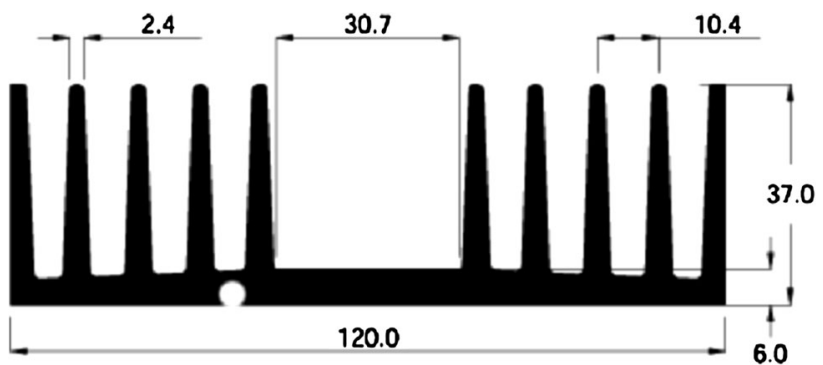

Fig. 3 Geometrical properties of the heat sink used for the tests (dimensions in $\mathrm{mm}$ )

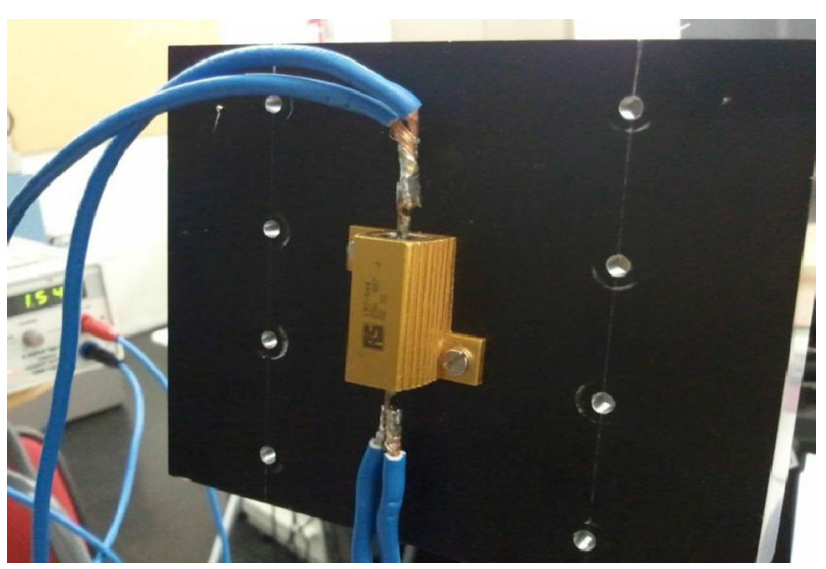

Fig. 4 Heat sink equipped with electrical resistance

It is characterised by a thermal resistance (linearised) towards the environment, declared by the manufacturer to be equal to $1.1\left(\mathrm{~K} \mathrm{~W}^{-1}\right)$, from a baseplate of $102 \mathrm{~mm} \times 120 \mathrm{~mm}$ and by a total of 10 fins placed symmetrically to the central cavity. In the tests carried out, the thermal load of the electrical component was simulated with a resistance positioned centrally on the surface opposite the fins (Fig. 4), whose theoretical power can vary from 25 to $60 \mathrm{~W}$.

The thermal camera used for the thermographic investigations was supplied by NEC, model TH7102MV (Fig. 5a), with a resolution of $0.08{ }^{\circ} \mathrm{C}$ at $30^{\circ} \mathrm{C}$ and a measurement range from -20 to $100{ }^{\circ} \mathrm{C}$ and with a $48 \mathrm{~mm}$ objective. Emissivity can be set on the thermal camera and can vary from 0.1 to 1.0 with an increase of 0.01 . The software used for the elaboration of the thermographic images (Fig. 5b) is the MikroSpec v1.2 furnished by NEC. Such images contain all the information regarding the various measurement points (temperature, position and emissivity) and allow visualisation of the temperature distribution on the heat sink.

The power supply used to deliver electrical current to the resistance has three outputs for which the tension and current (DC) can be adjusted, and it is equipped with a digital display for the visualisation of the tension and 
Fig. 5 Experimental apparatus

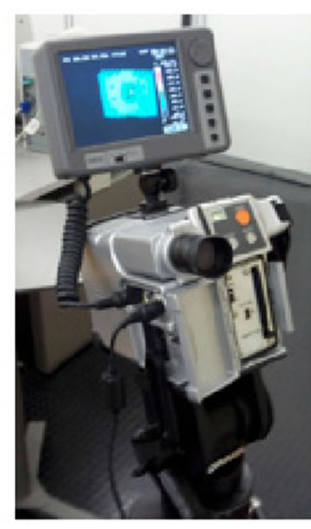

(a) NEC Thermo Tracer TH7102MV

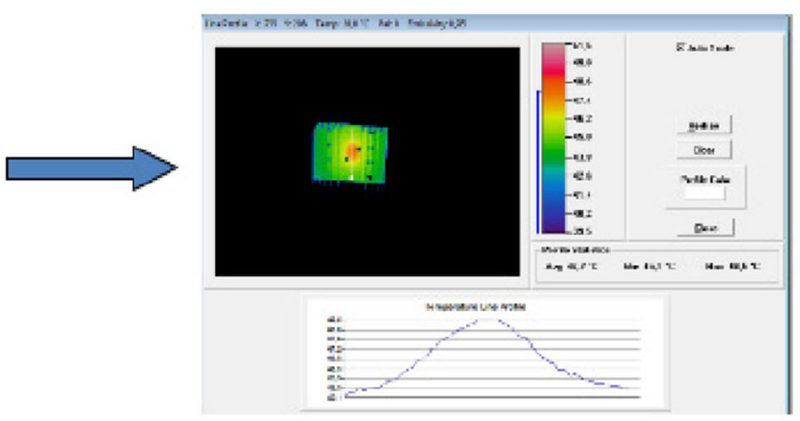

(b) MikroSpec v1.2 Software

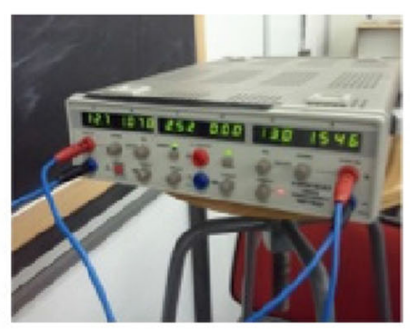

(c) Power supply

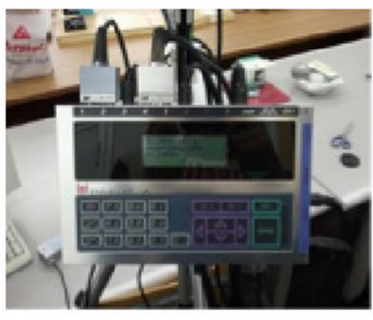

(d) Climatic data logger

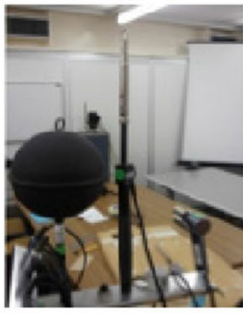

(e) sensors current values (Fig. 5c). The maximum tension, which can be supplied, is $32 \mathrm{~V}$ and a current equal to $2 \mathrm{~A}$ DC. There are $2 \mathrm{U}$ with output $0-32 \mathrm{~V}, 2 \mathrm{~A}$ and $1 \mathrm{U} 0-5.5 \mathrm{~V}, 5 \mathrm{~A}$. The power output is therefore equal to $64 \mathrm{~W}$ for the two canals $0-32 \mathrm{~V}$ and equal to $27.5 \mathrm{~W}$ for the output $0-5.5 \mathrm{~V}$. It is possible to obtain greater power output operating in a serial or parallel mode. In the case of the parallel mode of the two units with a potential difference equal to $32 \mathrm{~V}$, the resulting current is $4 \mathrm{~A}$ for a total power of $128 \mathrm{~W}$.

For the measurement of the environmental hygrothermal conditions, a portable climatic data logger, LSI Babuc/A (Fig. 5d), equipped with opportune probes and sensors, such as a psychrometer and an anemometer to measure air velocity (Fig. 5e), was used.

\section{Methodology used}

Once the electrical resistance and heat sink simulation models were created with ProENGINEER (Fig. 6), laboratory testing was started using the equipment as described in the previous paragraph. Resistance was set on the rear and central part of the heat sink and was connected to the power supply. The heat sink was positioned vertically and was placed frontally on a black surface with an approximate emissivity of 0.95 and at a distance to avoid local thermal exchange phenomenon, isolating as much as possible from unwanted thermal exchanges, such as conductive and radiative exchanges with other bodies.
The emissivity value for the heat sink used has been certified by the manufacturer. However, during the tests performed in the laboratory, the emissivity value has been set on the thermal camera and, using a thermocouple, was measured the temperature of various points of the heat sink and compared with the values resulting from the camera by varying the value of emissivity so long as the two values was coincident.

The experimental tests were carried out over following days since the attainment of steady state conditions has required a long time, since even though the environmental conditions were stable, some small temperature oscillations occurred. The meeting of stationary conditions is at the basis of the methodology used in that all the electrical energy absorbed must be dissipated in thermal energy. For each test, by means of the climatic data logger, the dry bulb and relative humidity temperature values were recorded. Furthermore, through the use of the hot-wire anemometer, fluid speed in the various cavities was measured, and it was found that the flow on all the plate surfaces and for all the range of powers applied resulted as being laminar.

By means of thermal camera monitoring, it was possible to observe the transitory phenomenon trend, and in the moment in which the stationary condition was met, a thermographic image of the heat sink temperature map was recorded. By analysing the image, the temperature of the different heat sink surfaces was obtained which is necessary in order to evaluate the flow and calculate all the fluid- 
Fig. 6 Models of the heat sink and of the thermal resistance created with ProENGINEER
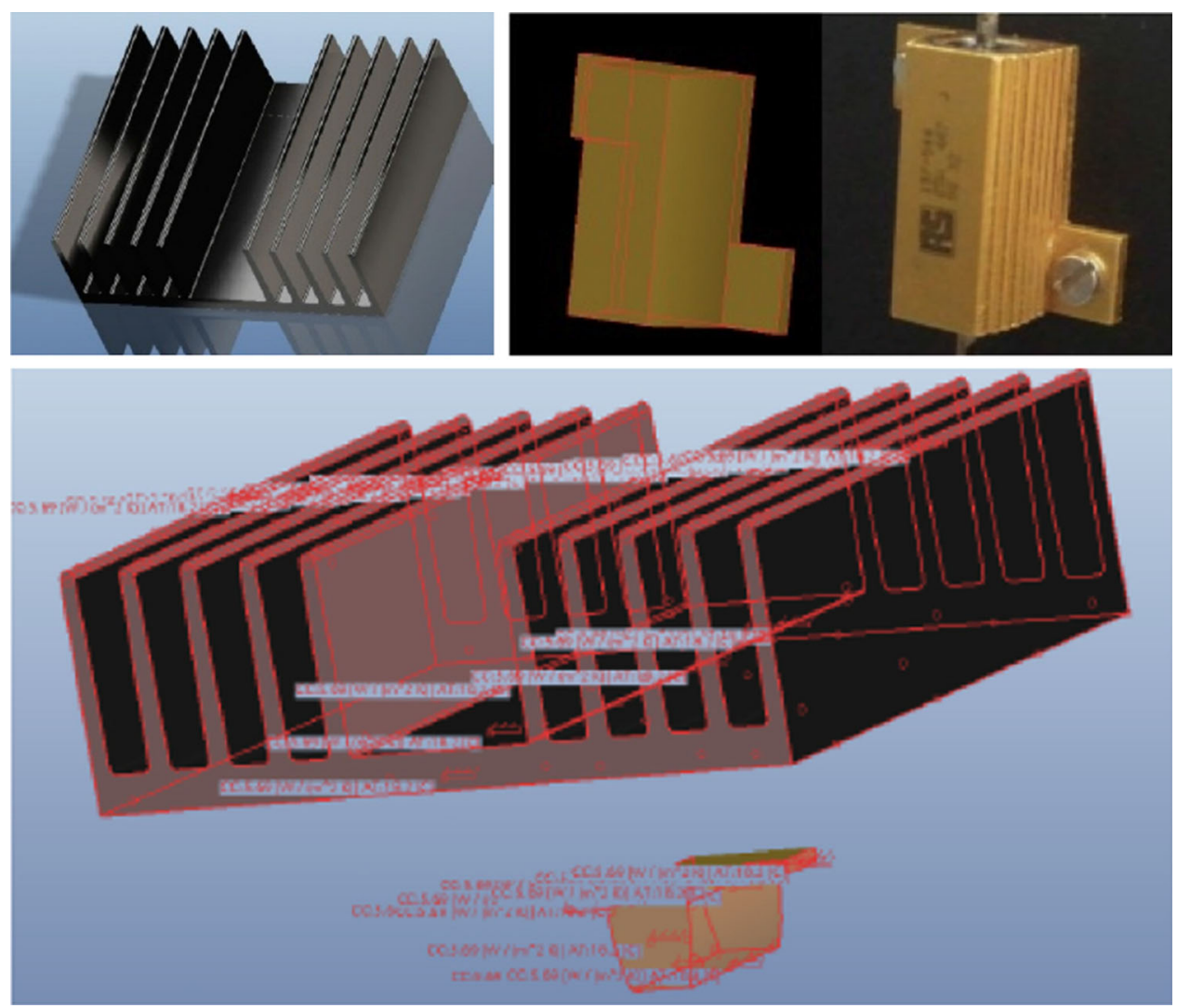

dynamic properties of the air of the same surfaces by means of the film temperature $t_{\text {film }}$.

The film temperature is defined as:

$t_{\mathrm{film}}=\frac{t_{\mathrm{p}}+t_{\mathrm{a}}}{2}$

where $t_{\mathrm{p}}$ is the fin surface temperature and $t_{\mathrm{a}}$ is the temperature of the fluid in the cavities.

Once the film temperature is determined, it was possible to estimate the convective heat exchange coefficient, utilising the well-known McAdams correlation:

$N u=0.55 \cdot R a^{0.25}$

By using the MicroSpec software, an analysis of the temperature maps for each individual test was carried out in order to find the correlation that provided the convective heat exchange coefficient which best approximates the obtained results. Due to the particular geometry and the natural convection conditions, the use of a single convective heat exchange value for the total area would not allow the obtainment of the real distribution of the temperatures on the heat sink by means of a simulation with ProENGINEER.

The convective coefficient value calculated with the theoretical method on the surface taken into consideration was the starting point for each individual test. Subsequently, proceeding with attempts and diverse simulations, the condition in which the convective coefficient values calculated provided the temperature distribution which best approximated those recorded with the thermal camera, was met. Once such coefficients were set on the different surfaces of the model created with ProENGINEER software and the surface thermal load produced by the resistance on the rear of the heat sink was applied, a finite elements analysis was carried out thus obtaining the experimental trend of the temperatures.

The method used is an iterative method and its control criterion is that to compare the real map of temperatures obtained through thermographic measurement with the map of temperatures obtained through the use of variable convective coefficients up to since in all points discretised using the FEM method, the temperature difference does not exceed $0.1{ }^{\circ} \mathrm{C}$, which corresponds to the minimum temperature difference that the thermal camera is able to estimate.

The algorithm that allows to obtain this result checks that the absolute error, $e=T_{\text {calc }, i}-T_{\text {exper }, i}$, is $<0.1{ }^{\circ} \mathrm{C}$. To simplify the problem, however, the heat sink has been divided into four zones that, from the thermographic measurement, showed different temperatures and, for these areas, were calculated the four values of the convective heat exchange coefficient. The algorithm implemented on 
Table 1 Geometrical characteristics of the heat sink

\begin{tabular}{llll}
\hline Fins & \multicolumn{3}{l}{ Cavity } \\
\hline Length & $102 \mathrm{~mm}$ & Apex width & $7.95 \mathrm{~mm}$ \\
Height & $29 \mathrm{~mm}$ & Root width & $6.70 \mathrm{~mm}$ \\
Apex thickness & $2.4 \mathrm{~mm}$ & & \\
Root thickness & $3.5 \mathrm{~mm}$ & & \\
\hline
\end{tabular}

Matlab allows to assign to the four areas, in the next step, the values of the convective heat exchange coefficients for which the whole temperature distribution presented a minimum RMS value.

$\mathrm{RMS}=\sqrt{\frac{1}{n} \times \sum_{i=1}^{n}\left(\frac{T_{\mathrm{calc}, i}-T_{\text {exper }, i}}{T_{\text {exper }, i}}\right)^{2}}=\min$

The dimensions of the heat sink, those taken into consideration in the calculations of the convective heat exchange coefficient with the correlation, are reported in Table 1 . The heat sink was divided into four critical zones (Fig. 7), in correspondence of which different convective coefficient values were used. The radiative effect was overlooked due to the low operating temperatures reached by the heat sink.

The upper and lower surfaces of the heat sink, the rounded summit of the fins, the rear surface and the internal fin surfaces which face the central cavity are indicated with $S_{\text {esp }}$ (Fig. 7a). $S_{\text {int }}$ indicates the internal surface of the fins, which includes all the interstices between the heat sink fins being subject to convective exchange of different entities and air speed different from the rest of the heat sink
(Fig. 7b). The central cavity surface, $S_{\text {cav }}$ (Fig. 7c), is the zone in which the highest temperatures are recorded, while the external surface of the fins at the extremities is indicated with $S_{\text {estr }}$ (Fig. 7d).

This type of numerical analysis was carried out by Culham et al. [7] and [8], by Narasimhan [9], Higuera and Ryazantsev [10], Da Silva et al. [11] and Floryan and Novak [12], even with different hypotheses than those considered in this study. Moreover, in the literature, there are studies on natural convention in heat sinks varying the thickness of the fins and the width of the cavity (Kim et al. [13]) with unrealistic hypotheses, in that isothermal and insulated heating surfaces were used in order to obtain thermal conditions similar to those discussed in the literature and for which it is possible to obtain an analytical solution. In the literature, there are studies which characterise the performance of heat sinks in forced convention (Hussam and Axcell [14]), always based on the hypothesis of classical operating.

In scientific literature, the inverse problem of determining the convective heat exchange coefficient from temperature distribution has been widely investigated as well as reported in the references [15-20].

In references [15] and [16], the thermographic measurements were carried out with reference to a thin plate of copper. In Ref. [17] are compared various calculation methods that allow the measurement of the temperatures in transitory regime and further traced back to the convective heat exchange coefficient. In Ref. [19] are applied, with reference to the composite materials, calculation methods similar to those described above in the presence of
Fig. 7 Subdivision of the heat sink into four critical zones

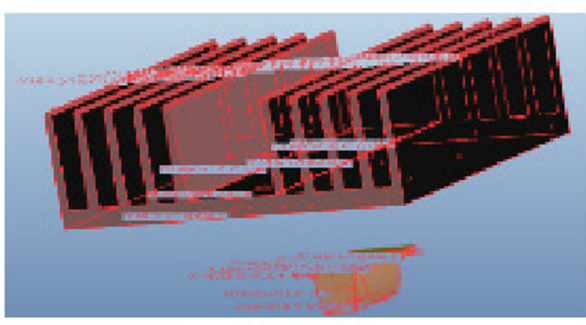

(a) $\mathrm{S}_{\mathrm{ssp}}$

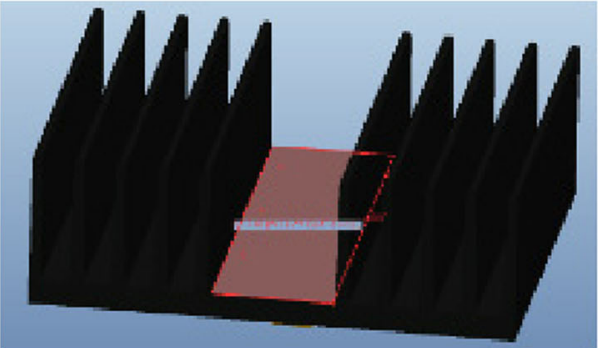

(c) $\mathrm{S}_{\mathrm{caw}}$

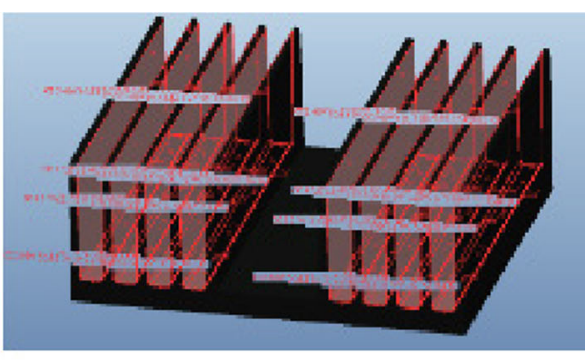

(b) $S_{\text {int }}$

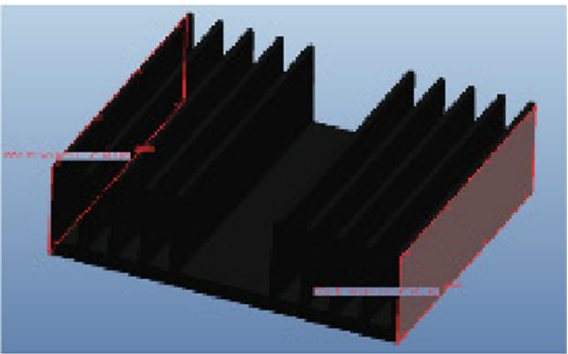

(d) $\mathrm{S}_{\text {estr }}$ 
Table 2 Data relative to the calculation of the convective heat exchange coefficients for the first test

\begin{tabular}{lllllll}
\hline & $\begin{array}{l}t_{\max } \\
\left({ }^{\circ} \mathrm{C}\right)\end{array}$ & $\begin{array}{l}t_{\text {film }} \\
\left({ }^{\circ} \mathrm{C}\right)\end{array}$ & $\operatorname{Pr}(-)$ & $R a(-)$ & $N u(-)$ & $h\left(\mathrm{Wm}^{-2} \mathrm{~K}\right)$ \\
\hline$S_{\text {esp }}$ & 45.4 & 32.1 & 0.713 & 2490931 & 21.85 & 5.69 \\
$S_{\text {int }}$ & 44.2 & 31.1 & 0.713 & 2347277 & 21.53 & 5.60 \\
$S_{\text {cav }}$ & 48.6 & 33.4 & 0.712 & 2670623 & 22.23 & 5.82 \\
$S_{\text {estr }}$ & 41.8 & 30.6 & 0.713 & 2787031 & 22.47 & 5.83 \\
\hline
\end{tabular}

radiative heat exchange. In Ref. [20], the method of Tikhonov is used, in addition to the method of Nelder-Mead, for a two-dimensional case.

\section{Experimental tests}

Five experimental tests were conducted with powers to be dissipated of between 9.2283 and $30.861 \mathrm{~W}$, while the dry bulb temperature of the environment air varied between 18.2 and $20.84{ }^{\circ} \mathrm{C}$.

The time required by the heat sink to reach stationary conditions, from an initial starting temperature equal to the environment temperature, was on average $20 \mathrm{~min}$, after which it was possible to acquire a thermographic image of the heat sink temperature map.

For the first test, a tension of $9.6 \mathrm{~V}$ was applied to the resistance, which simulates the electrical component, and a continual current equal to 2.12 A was supplied, obtaining a total power equal to $20.352 \mathrm{~W}$. The heat sink took around $20 \mathrm{~min}$ to reach the stationary regime, cooled down until the dry bulb environment temperature equal to $18.2^{\circ} \mathrm{C}$. The parameters used during the first test for the calculation of the initial heat exchange convective coefficients for the four surfaces are reported in Table 2.

The maximum temperature reached by the heat sink in the centre of the cavity is equal to $t_{\text {cav }}=48.6{ }^{\circ} \mathrm{C}$ (point 1 ), while the exposed surface reaches a temperature of $t_{\text {esp }}=45.4^{\circ} \mathrm{C}$ (point 2). In the interstice between the two most distant fins from the centre, the temperature is equal to $t_{\text {int }}=44.2{ }^{\circ} \mathrm{C}$ (point 3), and on the lateral surface of the fin closest to the cavity, a temperature equal to $46.4{ }^{\circ} \mathrm{C}$ (point 4) is observed. The average temperature of the heat sink resulted as being equal to $t_{\text {mean }}=45^{\circ} \mathrm{C}$ (Fig. 8).

Utilising such temperatures for the calculation of the convective heat exchange coefficients in the ProENGINEER simulation, the map reported in Fig. 9 is obtained. It is possible to note that the temperature distribution obtained is very different from the experimental values recorded, with differences in the region of $10-13{ }^{\circ} \mathrm{C}$; therefore, the correlation used is not appropriate.

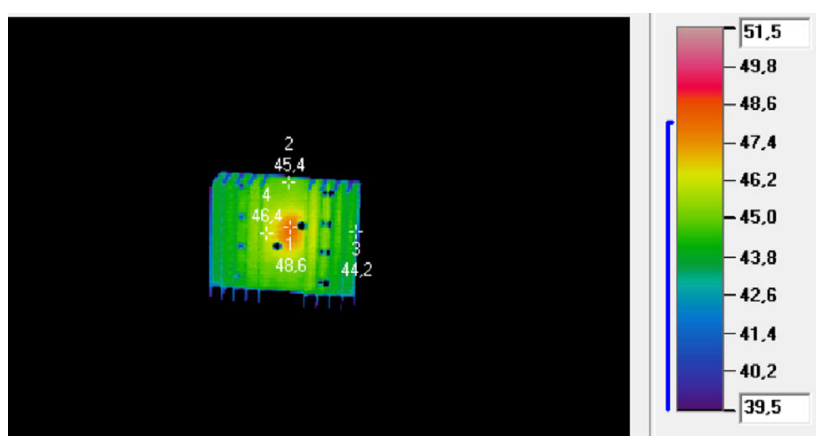

Fig. 8 Thermographic image of the heat sink for the first test

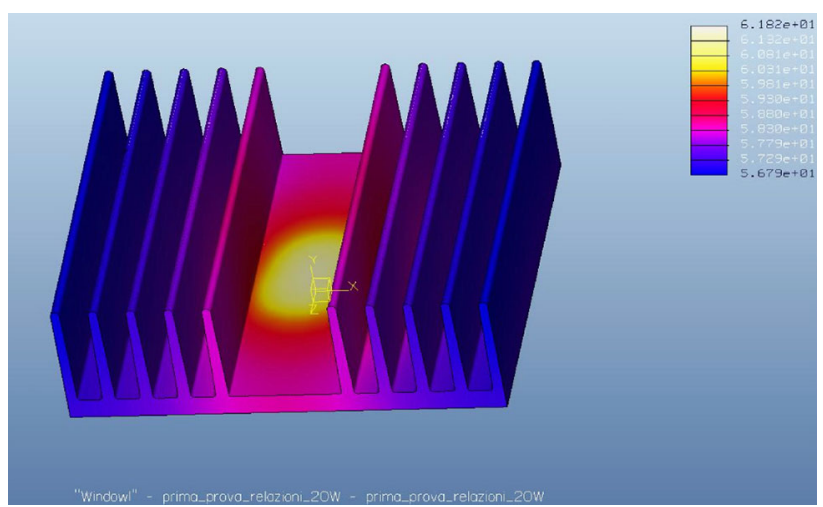

Fig. 9 Temperature map obtained with ProENGINEER with a sole convective heat exchange coefficient for the first test

The convective coefficients obtained after several attempts and for each surface examined are the following: $h_{\text {esp }}=8.6\left(\mathrm{Wm}^{-2} \mathrm{~K}\right), h_{\text {int }}=8.4\left(\mathrm{Wm}^{-2} \mathrm{~K}\right), h_{\text {cav }}=8.4$ $\left(\mathrm{Wm}^{-2} \mathrm{~K}\right)$ and $h_{\mathrm{estr}}=8.6\left(\mathrm{Wm}^{-2} \mathrm{~K}\right)$. The final result obtained with ProENGINEER comparing it with the starting thermographic image is reported in Fig. 10.

During the course of the following days, four further tests were conducted using the same procedure as the first test. The most relevant data relating to the five tests, temperature of the four surfaces and the average heat sink temperature, are reported in Table 3 .

The comparison between the experimental values ( $\left.h_{\text {exper }}\right)$ of the convective coefficient and those calculated with the correlation $\left(h_{\text {calc }}\right)$ for the four surfaces and for all the experimental tests is reported in Table 4.

The final column $\left(h_{\text {mean }}\right)$ refers to the average values of the convective coefficient for the four surfaces and therefore for the entire heat sink.

Comparisons, for the different heat sink surfaces, between the theoretical convective coefficient calculated with the correlation and the experimental ones obtained by 

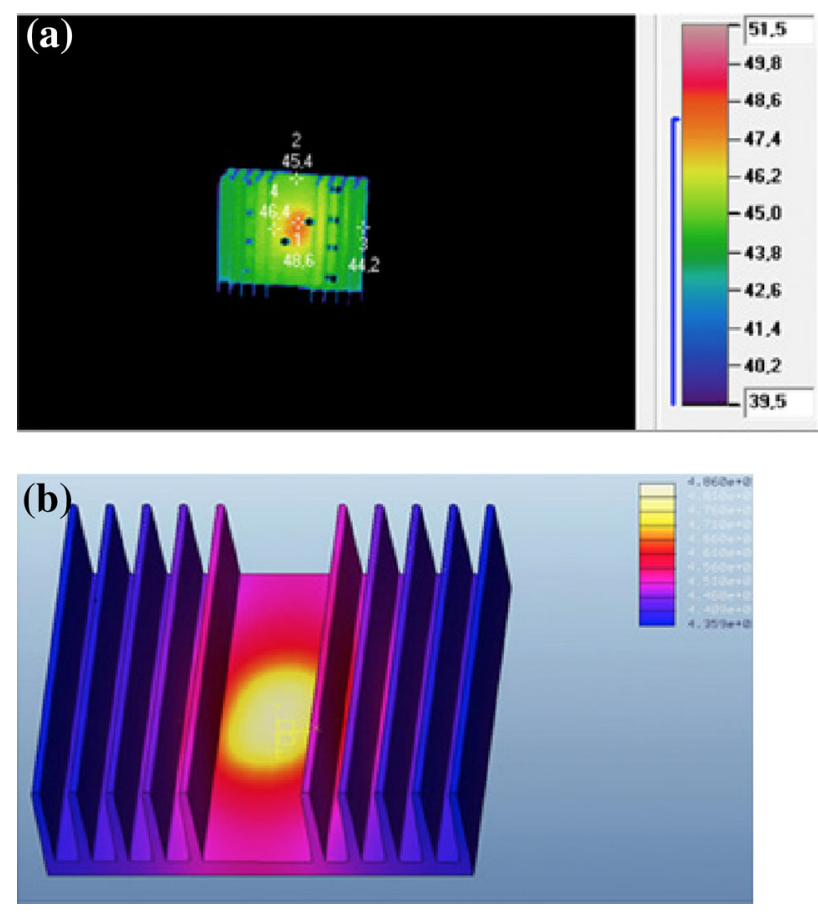

Fig. 10 Final map of the experimental temperatures (a) and calculated temperatures (b) for the first test

means of an analysis using ProENGINEER are reported in the diagrams in Figs. 11, 12, 13, 14.

\section{Comparison of the manufacturer's data and the correlation proposed for average values}

The possibility of using a mean heat convective exchange coefficient on all the surfaces of the heat sink, in such a way as to approximate the different point values calculated, was evaluated at this stage. From the comparison between the temperature maps obtained using the point values of the heat exchange coefficient and those obtainable using its average value, with similar power and environmental temperature of the test in consideration, it is possible to observe how the variation in temperature which occurs locally compared to the effective values, only varies for some tenths of centigrade degrees.

The average value of the convective heat exchange coefficient, for the five tests, is reported in Table 4.

The trend of the average values of the convective heat exchange coefficient in relation to the average temperature, both for experimental and theoretical values, is reported in Fig. 15. From the experimental trend values, it is possible to obtain the trend lines for the average convective coefficient in relation to the power dissipated:

$h_{\text {corr }}=-0.0055 \times Q_{\text {exper }}^{2}+0.3474 \times Q_{\text {exper }}+3.3615$

The power that is effectively dissipated by the electrical component can be calculated in relation to the experimental $\Delta T_{\text {exper }}$, with the correlation:

$Q_{\text {corr }}=0.0078 \times \Delta T_{\text {exper }}^{2}+0.4571 \times \Delta T_{\text {exper }}-0.2013$

Subsequently, the trend of the power dissipated in relation to the difference between the average temperature of the heat sink $t_{\text {mean }}$, and the environment temperature $t_{\mathrm{a}}$ was analysed:

$\Delta T=t_{\text {mean }}-t_{\mathrm{a}}$

The value of the typical resistance towards the environment supplied by the manufacturer, valid in stationary conditions, is equal to $R_{\text {manufact }}=1.1 \mathrm{KW}^{-1}$.
Table 3 Most relevant data for the five tests

Table 4 Comparison between the experimental convective coefficient values and those calculated with the manufacturer's data for the four surfaces and for the five tests and the average coefficients

\begin{tabular}{lrrrllllll}
\hline No. test & $V(\mathrm{~V})$ & \multicolumn{1}{c}{$I(\mathrm{~A})$} & $Q(\mathrm{~W})$ & $t_{\mathrm{a}}\left({ }^{\circ} \mathrm{C}\right)$ & $t_{\text {esp }}\left({ }^{\circ} \mathrm{C}\right)$ & $t_{\text {int }}\left({ }^{\circ} \mathrm{C}\right)$ & $t_{\text {cav }}\left({ }^{\circ} \mathrm{C}\right)$ & $t_{\text {estr }}\left({ }^{\circ} \mathrm{C}\right)$ & $t_{\text {mean }}\left({ }^{\circ} \mathrm{C}\right)$ \\
\hline Test no. 1 & 9.60 & 2.120 & 20.352 & 18.2 & 45.4 & 44.2 & 28.6 & 41.8 & 45 \\
Test no. 2 & 8.00 & 1.781 & 14.248 & 18.61 & 44.0 & 42.5 & 45.6 & 42.0 & 43 \\
Test no. 3 & 6.46 & 1.437 & 9.283 & 20.19 & 37.2 & 36.5 & 38.2 & 35.8 & 36 \\
Test no. 4 & 2.25 & 10.110 & 22.748 & 20.19 & 51.5 & 49.9 & 53.9 & 48.4 & 50 \\
Test no. 5 & 11.77 & 2.260 & 30.861 & 20.84 & 62.4 & 59.9 & 66.1 & 58.4 & 60 \\
\hline
\end{tabular}

\begin{tabular}{|c|c|c|c|c|c|c|c|c|c|c|}
\hline \multirow[t]{2}{*}{ No. test } & \multicolumn{2}{|c|}{$h_{\text {esp }}\left(\mathrm{Wm}^{-2} \mathrm{~K}\right)$} & \multicolumn{2}{|c|}{$h_{\text {int }}\left(\mathrm{Wm}^{-2} \mathrm{~K}\right)$} & \multicolumn{2}{|c|}{$h_{\text {cav }}\left(\mathrm{Wm}^{-2} \mathrm{~K}\right)$} & \multicolumn{2}{|c|}{$h_{\text {estr }}\left(\mathrm{Wm}^{-2} \mathrm{~K}\right)$} & \multicolumn{2}{|c|}{$h_{\text {mean }}\left(\mathrm{Wm}^{-2} \mathrm{~K}\right)$} \\
\hline & $h_{\text {calc }}$ & $h_{\text {exper }}$ & $h_{\text {calc }}$ & $h_{\text {exper }}$ & $h_{\text {calc }}$ & $h_{\text {exper }}$ & $h_{\text {calc }}$ & $h_{\text {exper }}$ & $h_{\text {calc }}$ & $h_{\text {exper }}$ \\
\hline Test no. 1 & 5.69 & 8.60 & 5.60 & 8.40 & 5.82 & 8.40 & 5.83 & 8.60 & 5.73 & 8.50 \\
\hline Test no. 2 & 5.57 & 6.40 & 5.49 & 6.50 & 5.65 & 6.40 & 5.66 & 6.70 & 5.59 & 6.50 \\
\hline Test no. 3 & 5.05 & 6.30 & 5.00 & 6.50 & 5.12 & 6.40 & 5.13 & 6.70 & 5.08 & 6.43 \\
\hline Test no. 4 & 5.84 & 8.70 & 5.77 & 8.40 & 5.94 & 8.60 & 5.96 & 8.70 & 5.88 & 8.60 \\
\hline Test no. 5 & 6.24 & 8.90 & 6.15 & 8.50 & 6.36 & 8.70 & 6.38 & 8.90 & 6.28 & 8.75 \\
\hline
\end{tabular}




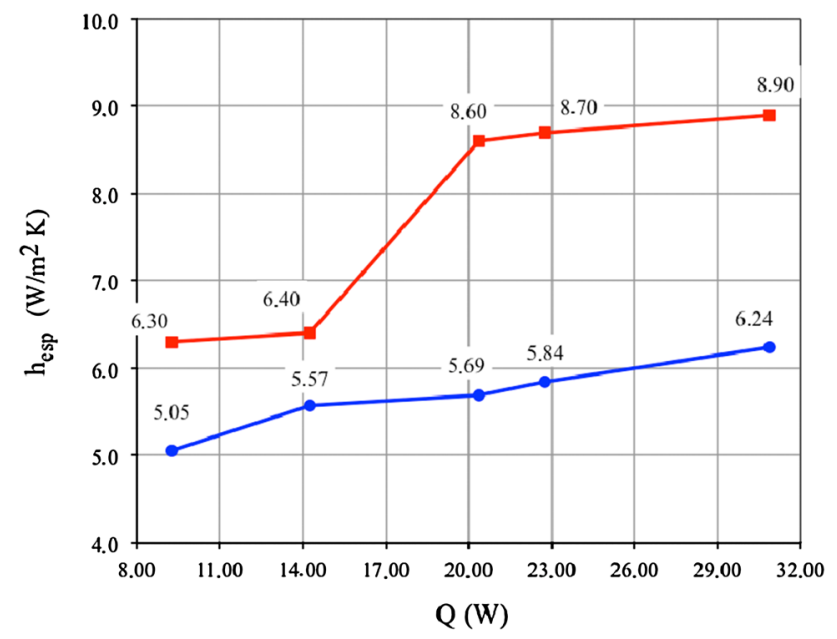

$\rightarrow$ Theoretical $\rightarrow-$ Experimental

Fig. 11 Trend of the theoretical and experimental convective heat transfer coefficient $h_{\text {esp }}$

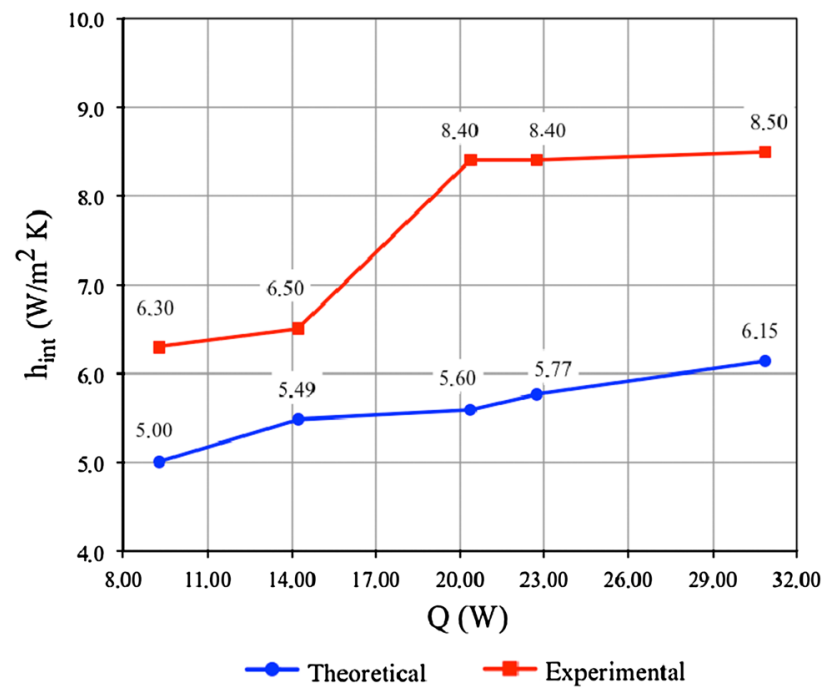

Fig. 12 Trend of the theoretical and experimental convective heat transfer coefficient $h_{\text {int }}$

Therefore, the dissipated thermal power, indicated with $Q_{\text {manufact }}\left(Q_{\text {manufact }}=\Delta T_{\text {exper }} / R_{\text {manufact }}\right)$, and the experimentally calculated dissipated thermal power, indicated with $Q_{\text {exper }}$ (Table 5), were calculated for the different tests. The thermal resistance values calculated experimentally $\left(R_{\text {exper }}=\Delta T_{\text {exper }} / Q_{\text {exper }}\right)$ are reported in Table 5 .

The trends of the two powers are reported in Fig. 16. The power obtained with the resistance supplied by the manufacturer provides values for the dissipated power which are much higher than the total thermal power supplied to the system. Such conditions during the project phase would mean that an electrical component set on the heat sink could dissipate much more power.

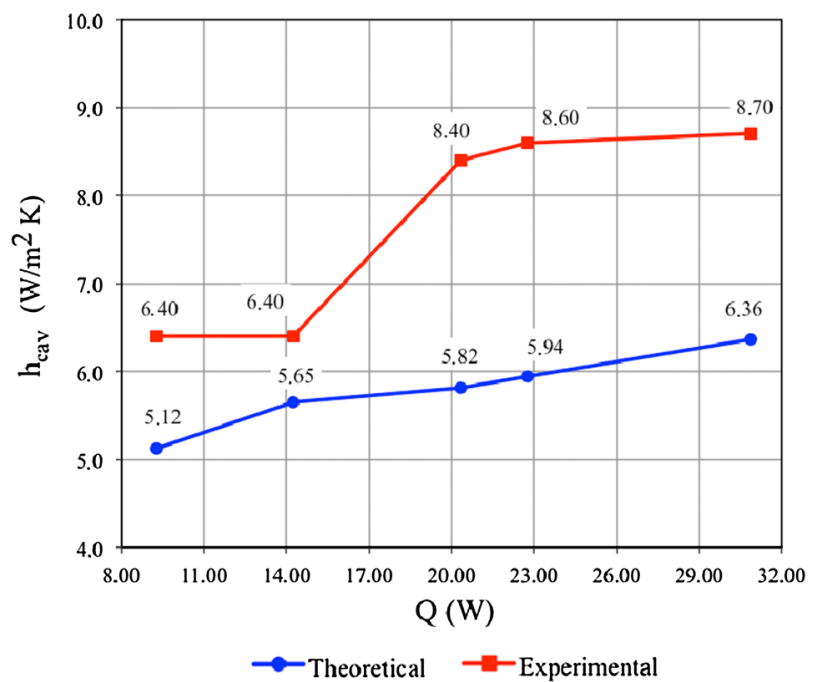

Fig. 13 Trend of the theoretical and experimental convective heat transfer coefficient $h_{\text {cav }}$

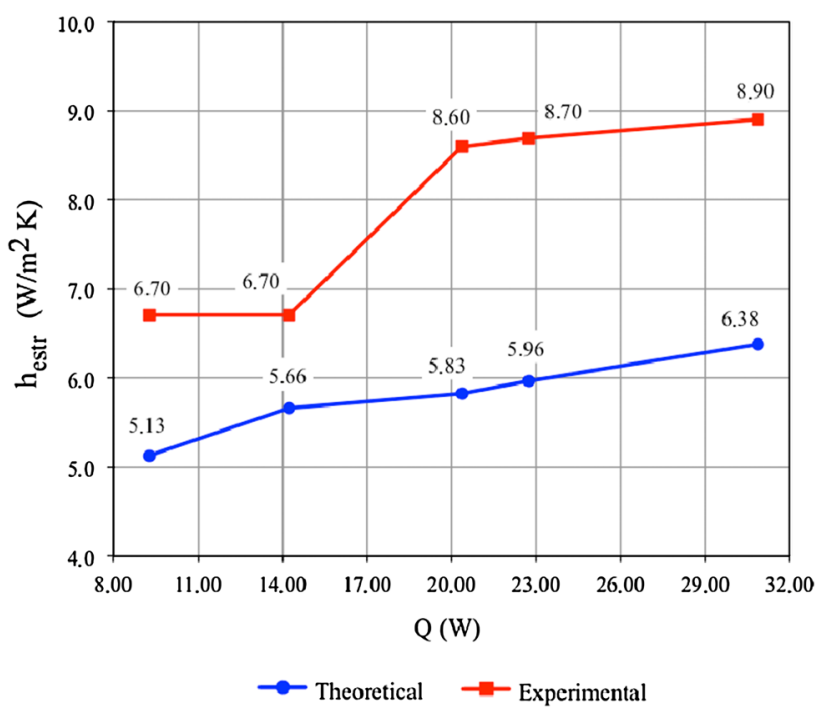

Fig. 14 Trend of the theoretical and experimental convective heat transfer coefficient $h_{\text {estr }}$

It is important to specify that the temperature range investigated in this paper is such as to consider negligible the effects of radiative heat exchange and the use of a mean convective heat exchange coefficient; the case of the heat sink under consideration can be considered as a good solution due to the fact that for the calculation of the dissipated power, the local $\Delta T$ is not used but the mean $\Delta T$, obtained from the mean temperature of the heat sink and the air temperature. Moreover, given the low variability of the convective heat exchange coefficient, even the areas at a higher temperature having small heat exchange areas dissipate power as the surfaces are with larger areas but with lower temperature gradient. 


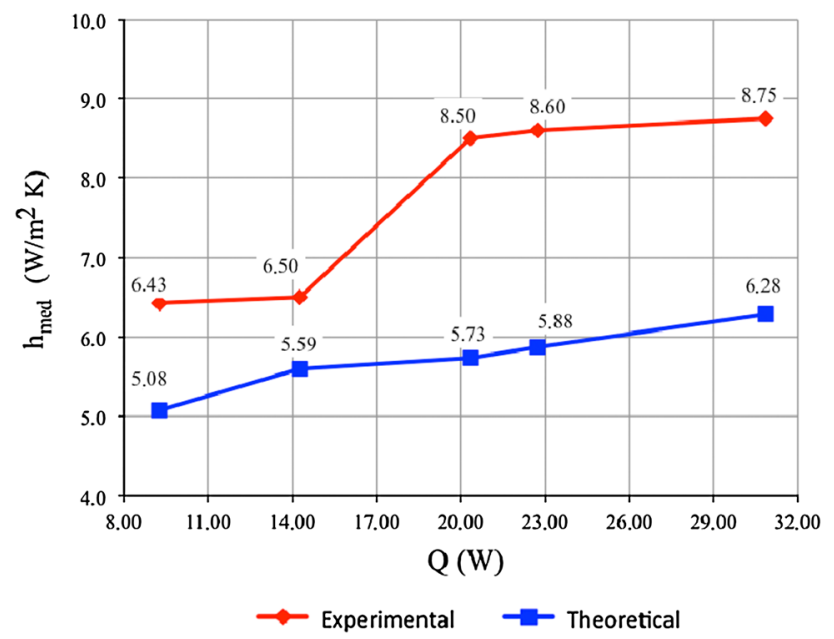

Fig. 15 Comparison between the average theoretical and experimental values of the convective heat transfer coefficient $h_{\text {med }}$

Table 5 Experimental power values $\left(Q_{\text {exper }}\right)$ and those calculated with the manufacturer's data $\left(Q_{\text {manufact }}\right)$

\begin{tabular}{lrrcrr}
\hline & $\begin{array}{l}\text { Test } \\
\text { no. } 1\end{array}$ & \multicolumn{1}{c}{$\begin{array}{l}\text { Test } \\
\text { no. } 2\end{array}$} & $\begin{array}{l}\text { Test } \\
\text { no. 3 }\end{array}$ & $\begin{array}{l}\text { Test } \\
\text { no. } 4\end{array}$ & $\begin{array}{l}\text { Test } \\
\text { no. 5 }\end{array}$ \\
\hline$\Delta T_{\text {exper }}\left({ }^{\circ} \mathrm{C}\right)$ & 26.80 & 24.39 & 15.81 & 29.81 & 39.16 \\
$Q_{\text {exper }}(\mathrm{W})$ & 20.35 & 14.24 & 9.283 & 22.74 & 30.86 \\
$R_{\text {exper }}\left({ }^{\circ} \mathrm{C} / \mathrm{W}\right)$ & 1.32 & 1.71 & 1.70 & 1.31 & 1.27 \\
$Q_{\text {manufact }}(\mathrm{W})$ & 24.36 & 22.17 & 14.37 & 27.10 & 35.60 \\
\hline
\end{tabular}

The uncertainty of the experimental measurement of the surface temperature $T(x, y)$ of the measuring point is linked to the two variables $x$ and $y$ [21].

Indicating the absolute uncertainty of the temperature at a point $P(x+\mathrm{d} x, y)$ with $u_{x}$, and the absolute uncertainty of the temperature at a point $P(x, y+\mathrm{d} y)$ with $u_{y}$, was analysed the combined uncertainty on the temperature $u_{T}$ with the expression:

$u_{T}=\sqrt{\left(\frac{\partial T(x, y)}{\partial x}\right)^{2} \times u_{x}^{2}+\left(\frac{\partial T(x, y)}{\partial y}\right)^{2} \times u_{y}^{2}}$

The percentage uncertainty is given by the equation:

$\left(\frac{u_{T}}{T(x, y)}\right) \times 100=\sqrt{\left(\frac{\partial u_{x}}{x} \times 100\right)^{2}+\left(\frac{\partial u_{y}}{y} \times 100\right)^{2}}$

The maximum percentage error of the camera is equal to $1 \%$, both along the $x$-direction and the $y$-direction, because the emissivity does not present spatial variations. Applying the Eq. (12), a value of the uncertainty on the measurement of the temperature $T(x, y)$ equal to $1.41 \%$ is obtained.

The error was defined with the relation:

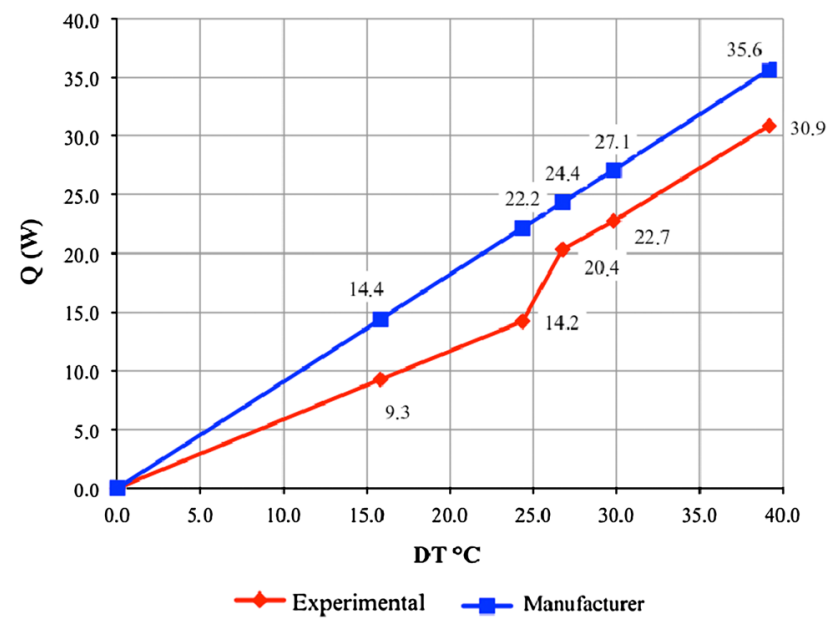

Fig. 16 Comparison of the experimental power $Q_{\text {exper }}$ and that calculated $Q_{\text {manufact }}$ with the manufacturer's data

$\varepsilon=\left(\frac{Q_{\text {manufact }}-Q_{\text {exper }}}{Q_{\text {manufact }}}\right) \times 100$

and the mean error as:

$\mathrm{MB}=\frac{\sum_{i}\left[\left(\frac{Q_{\text {manuffact }, i}-Q_{\text {exper }, i}}{Q_{\text {manuffact }, i}}\right) \times 100\right]}{N}$

Instead, the root mean square was defined with the following expression:

$\mathrm{RMS}=\sqrt{\frac{\sum_{i}\left[\left(\frac{\left.\left.Q_{\text {manufact }, i}-Q_{\text {exper }, i}\right) \times 100\right]^{2}}{Q_{\text {manuffact }, i}}\right.\right.}{N}}$

With reference to the experimental and theoretical data relating to the dissipated powers reported in Table 5 and in the graphic in Fig. 16, a mean error of $23.4 \%$ and RMS of $25.45 \%$ are obtained.

\section{Conclusions}

The objective of the present work is that of providing the guidelines, methodology and the instruments for the observation and characterisation of the convective phenomena of heat dissipation of electrical components and how the complexity of thermal exchange follows trends, which are not linear. However, this is not just a case study but has as its goal the finding of a possible link between thermographic measuring techniques and the analysis of finite elements, which cannot solely be based on the use of correlations, but in specific cases, it almost always requires an experimental confirmation. In this case, the study of new surfaces and complex geometrical forms or the properties of new materials for the removal of heat becomes possible. 
In the field of electronics, but also in other fields in which heat to be dissipated is involved, the main focus of research must not be the removal of heat produced in a manner that is collateral to the useful process, but rather its reduction with the aim of limiting thermal risks. In fact, the creation of components capable of working without an excessive production of heat would certainly eliminate costs linked to heat dissipation, but it would also be great progress from a viewpoint of environmental impact which, as is well known, has become the most urgent theme of the modern age in all aspects of daily life.

A further consideration regards the use of classical correlations from the literature, which when applied locally do not describe in an exact way the phenomenon of thermal exchange, indicating the flow conditions, even if it is evident from the trend of convective coefficient that after the third test, there is a discontinuity step in the calculation of the convective coefficient.

Moreover, since the values suggested by the manufacturer's characteristic curve are always greater than those recorded experimentally, it is inferred that in the planning phase, it is necessary to oversize the heat sink so as to avoid encountering overheating problems.

Open Access This article is distributed under the terms of the Creative Commons Attribution License which permits any use, distribution, and reproduction in any medium, provided the original author(s) and the source are credited.

\section{References}

1. Kraus, A.D., Bar-Cohen, A.: Design and analysis of heat sinks. Wiley, New York (1995)

2. Elenbaas, W.: Heat dissipation of parallel plates by free convection. Physica 9, 665-671 (1942)

3. Starner, K.E., McManus Jr, H.N.: An experimental investigation of free convection heat transfer from rectangular fin array. J. Heat Transf. 85, 273-278 (1963)

4. Welling, J.R., Wooldridge, C.B.: Free convection heat transfer coefficients from rectangular vertical fins. J. Heat Transf. 87, 439-444 (1965)

5. Van de Pol, D.W., Tierney, J.K.: Free convection Nusselt number for vertical unshaped channels. J. Heat Transf. 95, 542-543 (1973)
6. Bilitsky, A.: The effect of geometry on heat transfer by free convection from a fin array. MS Thesis, Department of Mechanical Engineering, Ben-Gurion University of the Negev, Beer Sheva, Israel (1986)

7. Culham, J.R., Lemcyzk, T.F., Lee, S., Yovanovich, M.M.: Meta- a conjugate heat transfer model for air cooling of circuit boards with arbitrary located heat sources. ASME Natl. Heat Transf. Conf. Heat Transf. Electron. Equip. HTD 171, 117-126 (1991)

8. Culham, J.R., Yovanovich, M.M., Lee, S.: Thermal modelling of isothermal cuboids and rectangular heat sinks cooled by natural convection. IEEE Trans. Compon. Packag. Manuf. Technol. A 18, 559-566 (1995)

9. Narasimhan, S., Majdalani, J.: Characterization of compact heat sink models in natural convection. IEEE Trans. Compon. Packag. Technol. 25, 78-86 (2002)

10. Higuera, F.J., Ryazantsev, Y.S.: Natural convection flow due to a heat source in a vertical channel. Int. J. Heat Mass Transf. 45, 2207-2212 (2002)

11. Da Silva, A.K., Lorente, S., Bejan, A.: Maximal heat transfer density in vertical morphing channels with natural convection. Numer. Heat Transf. A 45, 135-152 (2004)

12. Floryan, J.M., Novak, M.: Free convection heat transfer in multiple vertical channels. Int. J. Heat Fluid Flow 16, 244-253 (1995)

13. Kim, T.H., Do, K.H., Kim, D.K.: Closed form correlations for thermal optimization of plate-fin heat sinks under natural convection. Int. J. Heat Mass Transf. 54, 1210-1216 (2011)

14. Hussam, J., Axcell, B.P.: Modelling and simulation techniques for forced convection heat transfer in heat sinks with rectangular fins. Simul. Model. Pract. Theory 17, 871-882 (2009)

15. Orlande, H.R.B., Olivier, F., Maillet, D., Cotta, R.M.: Thermal measurements and inverse techniques. Taylor and Francis, New York (2011)

16. Bozzoli, F., Pagliarini, G., Rainieri, S.: Experimental validation of the filtering technique approach applied to the restoration of the heat source field. Exp. Therm. Fluid Sci. 44, 858-867 (2013)

17. Beck, J.V., Arnold, K.: Parameter estimation in engineering and science. Wiley Interscience, New York (1977)

18. Beck, J.V., Balckwell, B., Clair Jr, C.R.: Inverse heat conduction-III-posed problems. Wiley, New York (1985)

19. Alifanov, O.M.: Inverse heat transfer problem. Springer, Berlin (1994)

20. Bozzoli, F., et al.: Estimation of the local heat-transfer coefficient in the laminar flow regime in coiled tubes by the Tikhonov regularisation method. Int. J. Heat Mass Transf. 72, 352-361 (2014)

21. Dieck, R.H.: Measurements uncertainty, methods and application, 2nd edn. Instrument Society of America (ISA), Durham (1997) 